\title{
PENGARUH BAHAN DAN KADAR PENGISI DALAM PEREKAT EKSTERIOR TERHADAP KETEGUHAN REKAT KAYU LAPIS
}

\author{
M. I. Iskandar \\ Peneliti pada Pusat Penelitian dan Pengembangan Hasil Hutan \\ Jl. Gunung Batu No. 5, Bogor \\ e-mail: mi.iskandar53@gmail.com
}

\author{
ABSTRACT \\ Effect of Materials and Filler Content in Exterior Adhesion \\ for the Bonding Strength of Plywood
}

\begin{abstract}
Constraints that faced by the plywood industry today is the high cost of manufacture of plywood which are mainly due to the high cost of the adhesive, to lower the cost of the adhesive can be done by adding fillers (filler) into the glue mixture. The material is expected to assist in the process of adhesion, especially to reduce the excessive penetration of the adhesive into venir. The purpose of this study was to determine the effect of the material and content of filler in the bonding strength of the adhesive of plywood. Venir used in this study was peeled veneer measuring $40 \mathrm{~cm} \times 40 \mathrm{~cm}$ with a thickness of $1.5 \mathrm{~mm}$. Plywood was made of three layers with a thickness of $4.5 \mathrm{~mm}$. Type of adhesive used was liquid Phenol Formaldehyde (FF) with labor heavy of $170 \mathrm{~g} / \mathrm{m}^{2}$ for each surface (one line labor), venir formed felted cool for 10 minutes with a pressure of $10 \mathrm{~kg} / \mathrm{cm}^{2}$ followed by heat press at temperatures $140^{\circ} \mathrm{C}$, in the pressure of $10 \mathrm{~kg} / \mathrm{cm}^{2}$ for 5 minutes. Testing the bonding strength of plywood with the Indonesian National Standard. This research was conducted using the nested experimental design $3 \times 5$ with four replications. Factor A (filler) the level of three kinds, namely three kinds of flour. Factor B (filler content) were level five kinds, namely 0\%, 10\%, 20\%, $30 \%$ and $40 \%$. The results showed that the factor A (filler) was not significantly different, while factor $B$ (grade fillers) was very significant effect on the bonding strength of plywood.
\end{abstract}

Key words: material, content, fillers, exterior, bonding strength

\begin{abstract}
ABSTRAK
Kendala yang dihadapi oleh industri kayu lapis dewasa ini adalah tingginya biaya pembuatan kayu lapis yang pada umumnya disebabkan oleh tingginya biaya perekat, untuk menurunkan biaya perekat tersebut dapat dilakukan dengan cara menambahkan bahan pengisi (filler) ke dalam campuran perekat. Bahan tersebut diharapkan dapat membantu dalam proses perekatan, terutama untuk mengurangi penetrasi yang berlebihan dari perekat ke dalam venir. Tujuan penelitian ini adalah untuk mengetahui pengaruh bahan dan kadar pengisi dalam perekat eksterior terhadap keteguhan rekat kayu lapis. Venir yang digunakan dalam penelitian in adalah venir kupas berukuran $40 \mathrm{~cm}$ x $40 \mathrm{~cm}$ dengan ketebalan $1,5 \mathrm{~mm}$. Kayu lapis yang dibuat yaitu tiga lapis dengan ketebalan 4,5 mm. Jenis perekat yang digunakan adalah Fenol Formaldehida (FF) cair dengan berat labor $170 \mathrm{~g} / \mathrm{m}^{2}$ untuk setiap permukaan (satu garis labor), venir yang dibentuk dikempa dingin selama 10 menit dengan tekanan $10 \mathrm{~kg} / \mathrm{cm}^{2}$ kemudian dilanjutkan dengan kempa panas pada suhu $140^{\circ} \mathrm{C}$, tekanan kempa sebesar $10 \mathrm{~kg} / \mathrm{cm}^{2}$ selama 5 menit. Pengujian keteguhan rekat kayu lapis dengan Standar Nasional Indonesia. Penelitian ini dilakukan dengan menggunakan rancangan percobaan tersarang (nested) 3 x 5 dengan empat kali ulangan. Faktor A (pengisi) yang bertaraf tiga macam yaitu tiga macam tepung. Faktor B (kadar pengisi) yang bertaraf lima macam, yaitu $0 \%, 10 \%, 20 \%, 30 \%$ dan $40 \%$. Hasil penelitian menunjukkan bahwa faktor A (bahan pengisi) tidak berbeda nyata, sedangkan faktor B (kadar bahan pengisi) berpengaruh sangat nyata terhadap keteguhan rekat kayu lapis.
\end{abstract}

Kata kunci: bahan, kadar, pengisi, eksterior, keteguhan rekat

\section{PENDAHULUAN}

Perkembangan unit dan kapasitas produksi kayu lapis dilihat dari segi jenis kayu yang digunakan sebagai bahan baku menunjukkan suatu keadaan yang kurang menggembirakan. Sampai saat ini jenisjenis kayu yang digunakan untuk bahan baku industri kayu lapis masih terbatas kepada jenis-jenis tertentu seperti meranti, kapur dan keruing. 
Kecenderungan seperti ini kurang menguntungkan bagi perkembangan industri kayu lapis pada masa mendatang karena potensi jenis-jenis kayu tersebut akan menjadi langka akibat penebangan yang berlebihan. Salah satu usaha pemecahannya yaitu dengan memanfaatkan jenis-jenis lain yang selama ini belum banyak digunakan dalam industri kayu lapis termasuk sengon. Potensi jenis sengon sebagai bahan baku kayu lapis mempunyai masa depan yang cerah karena tanaman ini baik melalui kegiatan reboisasi maupun pembangunan hutan tanaman industri terus dikembangkan.

Kendala lain yang dihadapi oleh industri kayu lapis dewasa ini adalah tingginya biaya pembuatan kayu lapis yang disebabkan oleh tingginya biaya perekatan. Salah satu cara untuk menurunkan biaya perekatan yaitu dengan cara menambahkan bahan pengisi (filler) ke dalam ramuan perekat. Bahan tersebut sangat diperlukan karena dapat mengatur keteguhan rekat sedemikian rupa sehingga tetap mampu memenuhi persyaratan dan penurunan biaya perekatan dapat dicapai.

Tujuan penelitian ini adalah untuk mengetahui pengaruh bahan pengisi yang berupa tepung kapur, hanadex dan terak yang diramu ke dalam Fenol Formaldehida terhadap keteguhan rekat kayu lapis.

\section{BAHAN DAN METODE}

\section{Bahan}

Venir yang digunakan dalam penelitian ini adalah venir kupas dari kayu sengon (Paraserianthes falcataria). Perekat yang digunakan pada pembuatan kayu lapis dalam penelitian ini adalah Fenol Formaldehida, yang diperoleh dari PT Pamolite Adhesive Industry (PAI) Probolinggo, Jawa Timur. Bahan pengisi yang dipergunakan dalam penelitian ini adalah tepung hanadex, tepung kapur dan tepung terak.

\section{Metode}

Rancangan percobaan yang diperguna-kan dalam penelitian ini adalah percobaan tersarang (nested) $3 \times 5$ (Sujana, 2004).

Faktor bahan pengisi (faktor A) yang bertaraf tiga (tepung hanadex, tepung kapur dan tepung terak) dan factor kadar bahan pengisi (faktor B) yang berjumlah lima $(0 \%, 10 \%, 20 \%$, $30 \%$ dan $40 \%$ ) dimana faktor B tersarang dalam faktor A.

Tahap pembuatan kayu lapis yang dilakukan adalah sebagai berikut:

a. Ampelas venir yang berukuran $40 \mathrm{x}$ $40 \mathrm{~cm}$ sampai permukaannya halus, kemudian dikeringkan dalam oven sampai mencapai kadar air sekitar $10 \%$.

b. Labur permukaan venir dengan perekat campuran sebanyak 170 $\mathrm{g} / \mathrm{m}^{2}$.

c. Susun venir yang telah dilabur.

d. Kayu lapis yang telah selesai dirakit dikempa dingin selama 10 menit dengan tekanan $10 \mathrm{~kg} / \mathrm{cm}^{2}$ dan dilanjutkan dengan kempa panas pada suhu $140^{\circ} \mathrm{C}$ selama 5 menit.

e. Sebelum dibuat contoh uji, terlebih dahulu dilakukan pengondisian (conditioning) selama satu minggu.

Pembuatan contoh uji keteguhan geser tarik venir lamina dilakukan berdasarkan Standar Nasional Indonesia.

\section{HASIL DAN PEMBAHASAN}

\section{Komposisi Perekat}

Hasil pengukuran komposisi perekat dan kekentalan perekat pada masingmasing komposisi perekat dapat dilihat pada Tabel 1. Adanya perbedaan penambahn air dari masing-masing bahan pengisi diduga disebabkan karena komposisi kandungan kimia dan sifat fisik dari masing-masing bahan pengisi tidak sama. Komponen higroskopis terbanyak diperkirakan pada bahan pengisi tepung hanadex. 
Kadar Air

Hasil pengujian kadar air kayu lapis tercantum dalam Tabel 2. Dari table tersebut dapatdilihat bahwa niali kadar air berkisar antara $3,89 \%$ - 7,47\% dengan kadar air rata-rata $5,12 \%$ Persyaratan kadar air maksimum kayu lapis untuk SNI yaitu 14\%. Dengan demikian nilai kadar air kayu lapis memenuhi persyaratan SNI.

Tabel 1. Berat Masing-Masing Bahan dan Penambahan Air dalam Pembuatan Campuran Perekat Fenol Formaldehida

\begin{tabular}{|c|c|c|c|c|c|c|}
\hline \multicolumn{2}{|c|}{ Bahan Pengisi } & \multicolumn{3}{|c|}{ Komposisi Bahan Pengisi } & \multirow{2}{*}{$\begin{array}{l}\text { Air } \\
(\mathrm{mm})\end{array}$} & \multirow{2}{*}{$\begin{array}{c}\text { Kekentalan } \\
\text { (Poise) }\end{array}$} \\
\hline Macam & $\begin{array}{c}\text { Kadar } \\
(\%)\end{array}$ & $\mathrm{FF}$ & Filler & Hardener & & \\
\hline Tepung & 0 & 100 & 0 & 1,5 & 0 & 4,3 \\
\hline \multirow[t]{4}{*}{ Hanadex } & 10 & 100 & 10 & 1,5 & 0 & 11 \\
\hline & 20 & 100 & 20 & 1,5 & 20 & 19 \\
\hline & 30 & 100 & 30 & 1,5 & 40 & 17 \\
\hline & 40 & 100 & 40 & 1,5 & 110 & 19 \\
\hline Tepung & 0 & 100 & 0 & 1,5 & 0 & 4,3 \\
\hline \multirow[t]{4}{*}{ Kapur } & 10 & 100 & 10 & 1,5 & 0 & 4,7 \\
\hline & 20 & 100 & 20 & 1,5 & 0 & 6 \\
\hline & 30 & 100 & 30 & 1,5 & 0 & 6,2 \\
\hline & 40 & 100 & 40 & 1,5 & 0 & 8,2 \\
\hline Tepung & 0 & 100 & 0 & 1,5 & 0 & 4,3 \\
\hline \multirow[t]{4}{*}{ Terak } & 10 & 100 & 10 & 1,5 & 0 & 4,5 \\
\hline & 20 & 100 & 20 & 1,5 & 0 & 5 \\
\hline & 30 & 100 & 30 & 1,5 & 0 & 6 \\
\hline & 40 & 100 & 40 & 1,5 & 0 & 7,5 \\
\hline
\end{tabular}

Tabel 2. Hasil Pengujian Kadar Air

\begin{tabular}{cccccccc}
\hline \multicolumn{2}{c}{ Bahan Pengisi } & \multicolumn{9}{c}{ Ulangan } & Total & \multirow{2}{*}{$\begin{array}{c}\text { Rata- } \\
\text { Rata }\end{array}$} \\
\cline { 1 - 4 } Macam & Kadar $(\%)$ & 1 & 2 & 3 & 4 & & \\
\cline { 1 - 2 } Tepung & 0 & 5,03 & 5,51 & 5,14 & 5,67 & 21,35 & 5,34 \\
Hanadex & 10 & 5,38 & 4,56 & 5,14 & 4,25 & 19,33 & 4,83 \\
& 20 & 5,08 & 4,15 & 5,50 & 5,16 & 19,89 & 4,97 \\
& 30 & 3,89 & 4,25 & 4,78 & 4,22 & 17,14 & 4,29 \\
Tepung & 40 & 5,39 & 4,66 & 7,47 & 4,68 & 22,20 & 5,55 \\
Kapur & 0 & 5,03 & 5,51 & 5,14 & 5,67 & 21,35 & 5,34 \\
& 10 & 4,96 & 4,38 & 5,22 & 5,02 & 19,58 & 4,90 \\
& 20 & 5,13 & 5,33 & 5,28 & 5,60 & 21,34 & 5,34 \\
Tepung & 30 & 5,32 & 4,83 & 5,17 & 5,12 & 20,44 & 5,11 \\
Terak & 40 & 4,55 & 4,62 & 5,68 & 5,40 & 20,25 & 5,06 \\
& 0 & 5,03 & 5,51 & 5,14 & 5,67 & 21,35 & 5,34 \\
& 10 & 5,30 & 5,22 & 5,13 & 5,69 & 21,34 & 5,34 \\
& 30 & 5,03 & 5,26 & 4,91 & 4,67 & 19,87 & 4,97 \\
& 40 & 5,06 & 4,56 & 5,20 & 5,33 & 20,15 & 5,04 \\
& 5,21 & 5,24 & 5,99 & 5,02 & 21,14 & 5,37 \\
\hline
\end{tabular}




\section{Kerapatan}

Hasil pengujian kerapatan kayu lapis dapat dilihat pada Tabel 3. Dari Tabel 3 dapat dilihat bahwa nilai kerapatan kayu lapis ada diantara $0,36 \mathrm{~g} / \mathrm{cm}^{3}$ sampai dengan $0,53 \mathrm{~g} / \mathrm{cm}^{3}$ dengan kerapatan rata-rata $0,43 \mathrm{~g} / \mathrm{cm}^{3}$.

\section{Keteguhan Rekat}

Nilai rata-rata keteguhan rekat kayu lapis tercantum pada Tabel 4. Dari Tabel 4 dapat dilihat bahwa nilai keteguhan rekat dan kerusakan kayu untuk seluruh macam bahan pengisi yang terdiri dari tepung hanadex, tepung kapur dan tepung terak serta untuk seluruh kadar $(0 \%$, $10 \%, 20 \%, 30 \%$ dan $40 \%$ ) memenuhi SNI karena nilai keteguhan rekat tidak kurang dari $7 \mathrm{~kg} / \mathrm{cm}^{2}$.

Untuk mengetahui pengaruh macam dan kadar bahan pengisi terhadap keteguhan rekat kayu lapis dilakukan sidik ragam. Hasil analisis sidik ragam keteguhan rekat kayu lapis tercantum pada Tabel 5 .

Tabel 3. Hasil Pengujian Kerapatan $\left(\mathrm{g} / \mathrm{cm}^{3}\right)$

\begin{tabular}{cccccccc}
\hline \multicolumn{2}{c}{ Bahan Pengisi } & \multicolumn{9}{c}{ Ulangan } & Total & \multirow{2}{*}{$\begin{array}{c}\text { Rata- } \\
\text { Rata }\end{array}$} \\
\cline { 1 - 4 } Macam & Kadar $(\%)$ & 1 & 2 & 3 & 4 & & 0,40 \\
Tepung & 0 & 0,37 & 0,40 & 0,45 & 0,38 & 1,60 & 0,43 \\
Hanadex & 10 & 0,41 & 0,41 & 0,43 & 0,48 & 1,73 & 0,43 \\
& 20 & 0,39 & 0,46 & 0,39 & 0,44 & 1,68 & 0,42 \\
& 30 & 0,47 & 0,39 & 0,40 & 0,53 & 1,79 & 0,45 \\
Tepung & 40 & 0,39 & 0,52 & 0,34 & 0,44 & 1,69 & 0,45 \\
Kapur & 0 & 0,37 & 0,40 & 0,45 & 0,38 & 1,60 & 0,40 \\
& 10 & 0,41 & 0,50 & 0,42 & 0,44 & 1,77 & 0,44 \\
& 20 & 0,40 & 0,43 & 0,46 & 0,47 & 1,76 & 0,44 \\
Tepung & 30 & 0,47 & 0,45 & 0,44 & 0,44 & 1,80 & 0,45 \\
Terak & 0 & 0,36 & 0,41 & 0,46 & 0,38 & 1,61 & 0,40 \\
& 10 & 0,37 & 0,40 & 0,45 & 0,38 & 1,60 & 0,40 \\
& 20 & 0,39 & 0,40 & 0,47 & 0,47 & 1,73 & 0,43 \\
& 30 & 0,52 & 0,43 & 0,45 & 0,39 & 1,79 & 0,45 \\
& 40 & 0,42 & 0,48 & 0,39 & 0,48 & 1,79 & 0,45 \\
& & 0,43 & 0,42 & 0,48 & 1,75 & 0,44 \\
\hline
\end{tabular}

Tabel 4. Nilai Keteguhan Rekat

\begin{tabular}{cccc}
\hline \multicolumn{2}{c}{ Bahan Pengisi } & \multicolumn{2}{c}{ Nilai Rata-Rata } \\
\hline Macam & Kadar $(\%)$ & $\begin{array}{c}\text { Keteguhan Rekat } \\
\left(\mathrm{kg} / \mathrm{cm}^{2}\right)\end{array}$ & $\begin{array}{c}\text { Kerusakan Kayu } \\
(\%)\end{array}$ \\
\hline Tepung Hanadex & 0 & 12,19 & 82,50 \\
& 10 & 14,05 & 86,25 \\
& 20 & 14,76 & 67,50 \\
Tepung Kapur & 30 & 9,94 & 46,25 \\
& 40 & 9,68 & 41,25 \\
& 0 & 12,19 & 82,50 \\
& 10 & 14,58 & 78,75 \\
& 20 & 14,80 & 78,75 \\
& 30 & 11,09 & 86,25 \\
& 40 & 9,91 & 75,00 \\
& 0 & 12,19 & 82,50 \\
& 10 & 15,29 & 92,50 \\
& 20 & 17,39 & 76,25 \\
& 30 & 11,15 & 95,00 \\
& 40 & 9,85 & 92,50 \\
\hline
\end{tabular}


Tabel 5. Hasil Sidik Ragam Keteguhan Rekat

\begin{tabular}{lcccccc}
\hline \multicolumn{1}{c}{$\begin{array}{c}\text { Sumber } \\
\text { Keragaman }\end{array}$} & $\begin{array}{c}\text { Derajat } \\
\text { Bebas }\end{array}$ & $\begin{array}{c}\text { Jumlah } \\
\text { Kuadrat }\end{array}$ & $\begin{array}{c}\text { Kuadrat } \\
\text { Tengah }\end{array}$ & F Hitung & \multicolumn{2}{c}{ F Tabel } \\
\cline { 6 - 7 } Rata-rata & 1 & 9540,22 & & & $5 \%$ & $1 \%$ \\
Macam & 2 & 11,27 & 5,64 & $0,22^{\mathrm{TN}}$ & 3,21 & 5,11 \\
pengisi & 12 & 314,38 & 26,20 & $8,71^{\mathrm{Xx}}$ & 1,96 & 2,61 \\
Kadar pengisi & 45 & 135,42 & 3,01 & & & \\
Galat & \multicolumn{1}{c}{ Total } & 60 & 10001,30 & & & \\
\hline Keterangan: & \multicolumn{1}{c}{ TN= Tidak Nyata pada Taraf 5\% } & & & \\
& XX= Sangat Nyata pada Taraf 1\% & & &
\end{tabular}

Berdasarkan hasil sidik ragam pada Tabel 5 bahwa macam bahan pengisi tidak berpengaruh nyata terhadap keteguhan rekat, dengan demikian kayu lapis yang memakai bahan pengisi tepung hanadex, tepung kapur dan tepung terak menghasilkan keteguhan rekat yang relatif sama.

Selain dari itu pada Tabel 5 bahwa nilai kadar bahan pengisi memberikan pengaruh yang sangat nyata terhadap keteguhan rekat. Semakin tinggi kadar bahan pengisi dalam ramuan perekat, semakin sedikit perekat Fenol Formaldehida per satuan luas permukaan venir, ini berarti nilai keteguhan rekatnya semakin turun. Namun demikian, dengan semakin meningkatnya kadar bahan pengisi sampai pada batas tertentu keteguh-an rekat meningkat, akan tetapi setelah kadar bahan pengisi melebihi batas tersebut keteguhan rekat akan menurun.

Penambahan bahan pengisi sampai pada batas kadar tertentu cenderung mening-katkan keteguhan rekat, hal ini disebabkan karena adanya peningkatan kekentalan perekat sehingga jumlah perekat yang meresap ke dalam venir tidak terlalu banyak dan garis perekat terlampau tipis. Apabila penambahan bahan pengisi telah melebihi batas kadar optimum keteguhan rekat maka kadar resin Fenol Formaldehida pada garis perekat relatif rendah dan ini akan menurunkan keteguhan rekat kayu lapis (Sutigno, 1998 dalam Herawadi, 2007).

Berdasarkan hasil penelitian Perry (2007), yang menyebutkan bahwa penambahan bahan pengisi pada campuran perekat lebih dari $10 \%$ dari berat perekat akan menyebabkan penurunan keteguhan rekat walaupun hasilnya masih baik. Filoteo (2012) dan Kollman et al. (1995) menyatakan bahwa pemanfaatan bahan pengisi sebaiknya berkisar antara $10 \%$ sampai 20\%. Dari hasil penelitian pen-dahuluan yang menggunakan bahan pengisi tepung sekam padi berukuran 140 mesh pada pembuatan kayu lapis 3 lapis ternyata kualitas peningkatan keteguhan rekat tertinggi dicapai pada penambahan kadar 20\% (Xuan et al., 1997).

Melalui sidik ragam maka diketahui bahwa kadar bahan pengisi berpengaruh terhadap keteguhan rekat kayu lapis, selanjutnya untuk melihat hubungan antara kadar bahan pengisi dengan keteguhan rekat dilakukan analisis regresi. Sebagai model penduga atas dasar kecenderungan hu-bungan antara kadar bahan pengisi dengan keteguhan rekat maka dipilih model persamaan regresi kuadratik. Hal serupa dapat dijumpai pada hasil penelitian kayu lapis sengon yang menggunakan bahan pengisi tepung onggok, tepung tempurung kelapa dan tepung sabut kelapa sawit dengan menggunakan perekat urea formaldehida (Herawadi, 2007).

Dari perhitungan uji beda nyata jujur bahwa kadar bahan pengisi $40 \%$ tidak berbeda nyata dengan kadar 30\% dan $0 \%$, tetapi berbeda nyata dengan kadar $10 \%$ dan $20 \%$, sedangkan untuk kada $30 \%, 0 \%, 10 \%$ dan $20 \%$ tidak berbeda nyata. 


\section{$40 \% \quad 30 \% \quad 0 \% \quad 10 \% \quad 20 \%$}

Keterangan

$=$ Tidak nyata pada taraf $1 \%$

\section{KESIMPULAN}

1. Kadar air kayu lapis berkisar antara $3,89 \%$ - 7,47\% dengan rata-rata $5,12 \%$ memenuhi persyaratan Standar Nasional Indonesia.

2. Nilai keteguhan rekat kayu lapis yang memakai bahan pengisi tepung hanadex, tepung kapur dan tepung terak untuk semua kadar yang berkisar antara $9,68 \mathrm{~kg} / \mathrm{cm}^{2}-17,39$ $\mathrm{kg} / \mathrm{cm}^{2}$ memenuhi Standar Nasional Indonesia karena tidak kurang dari 7 $\mathrm{kg} / \mathrm{cm}^{2}$.

3. Hasil sidik ragam keteguhan rekat kayu lapis menunjukkan bahwa faktor A (macam bahan pengisi) relatif mempunyai kesamaan sifat dan fungsi sebagai bahan pengisi kayu lapis sehingga dapat diduga pemakaian ketiga jenis bahan pengisi ini akan memberikan nilai keteguhan rekat yang relatif sama. Sedangkan faktor B (kadar bahan pengisi) untuk keseluruhan bahan pengisi memberikan nilai keteguhan rekat yang bervariasi.

\section{DAFTAR PUSTAKA}

Anonim. 2000. Standar Mutu dan Uji Kayu Lapis Standar Nasional Indonesia (SNI 01-2704-2000).

Filoteo, A. G. 2002. Filler dan Externders. Technical Notes No. 117. Forest Product Research and Industries Development Commission. Los Banos.
Herawadi. 2007. Pengaruh Pemakaian Tepung Onggok, Tempurung Kelapa dan Sabut Kelapa Sawit sebagai Bahan Pengisi pada Perekat U F terhadap Keteguhan Rekat Kayu Lapis Sengon. Fakultas Kehutanan Unwim Bandung. Tidak Diterbitkan.

Kollman F. P. P. E. W. Kuenzi and A. J. Stamn. 1995. Principles of Wood Science and Technology. Vol. II Wood Based Materials. SpringerVertag-Berlin-Heidelberg-New York.

Sudjana. 2014. Desain dan Analisis Eksperimen. Bandung: Tarsito.

Xuan, B. F. S. Polliscvo and R. C. Casilla. 1997. Ricc Hull Powder as Glue Filler in Plywood Manufacture. Part I. Effect on Bond Quality. The Phillipine Lumberman. 20 (10): 26-30. 